\title{
Effect of Environmental Enrichment on the Body Weight in Broiler Chickens
}

http://dx.doi.org/10.1590/1806-9061-2019-1130

-Author(s)

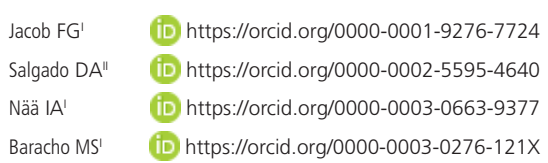

Baracho MS' iD https://orcid.org/0000-0003-0276-121X

School of Agricultural Engineering, University of Campinas, 13083-875, Campinas, Brazil.

School of Sciences and Engineering, São Paulo

State University, 17602-496, Tupã, Brazil.

\section{-Mail Address}

Corresponding author e-mail address Irenilza Alencar Nääs

Faculdade de Engenharia Agrícola - FEAGRI, Av. Cândido Rondon, 501 - Campinas,

13083-875, Brazil.

Phone: +551932521176

Email: irenilza@gmail.com

\section{nKeywords}

Broiler production; broiler welfare, music, light.

\section{ABSTRACT}

The present study had the objective of analysing the impact of the use of environmental enrichment (music and light stimuli), broiler sex, and age in broiler chickens' weight during growth. The observational study was carried out on a commercial farm. The environmental enrichment consisted of broilers' stimulation by sound and light, and a house was kept without stimulus (control). The music stimuli consisted of different music styles and was played during the experiment to promote motivation for the birds. The light stimuli came from a coloured (red and green) LED strobe projector. Both stimuli were applied once a day for about 6 minutes, for five weeks. The broilers were weighed at the end of each week of growth. Throughout the growth period, broiler behaviours were analysed weekly through videos, and the leg disorders of the birds were put into score evaluations. The effects of the environmental enrichment type, gender, and age, and the probable interactions of these variables, on the weight of the broiler chickens were analysed by the comparative analysis of means, analysis of variance (ANOVA), and Tukey test of multiple comparisons. 7, 14, and 21 day old broiler chickens did not differ on body weight when compared with age, gender, and environmental enrichment (broiler house) ( $p>0.05)$. Males from 21 days of age had an increase in body weight when compared with females. Light enrichment presented the lowest body weight when compared with all studied houses, while the absence of enrichment presented the highest broiler weight.

\section{INTRODUCTION}

In 2017, Brazil produced 13.056 million tons of broiler chicken meat and maintained the second position as the biggest meat producer and first position as worldwide exporter (ABPA, 2018). These achievements are the results of several factors as such a biosecurity control, climate, management, parents stock adaptation and own production of feeding sources, e.g., maize and soya although international trade could be affected by the increase in social responsibility and environmental consciousness (Mollo et al., 2009). On the report of Meluzzi et al. (2008) for the consumer's concerns like food quality, animal welfare, safety, and protection of the ecosystem have a much higher value.

According to ABPA (2018), 33\% of the Brazilian production goes to export, and nearly 300 million tons was used for trading to the EU in 2017. For Europe, animal welfare in poultry production is an essential topic (Robins \& Phillips,2011). Development requirements pose a likely threat to the market position of meat not produced in underdeveloped animal-welfare measures or without the guarantee that it was produced under such criteria (Kryeziu et al., 2018; Molento, 2005; Van Horne \& Achterbosch, 2008). On the report of the Brazilian Association of Alternative Poultry Production (AVAL), free-range broiler chicks represent only $0.5 \%$ of the production 
equivalent to 6 million broiler chicks per month, a number that increased 15\% in 2016 (Carreiro, 2017). Farmers are adjusting the broiler chickens barn from conventional to a dark environment (Dark House) due to achieve better performance. However, such a condition could affect meat exports because natural light can be a further welfare rule (Andreazzi et al., 2018). Related to animal welfare, Brazil does not have any legislation in the welfare of broiler chickens, e.g., regulation on the density of broiler chickens (Van Horne \& Achterbosch, 2008).

On the authority of DEFRA (2019) in 2018, England and Wales registered an average in live weights of $2.2 \mathrm{~kg}$ in broiler chicken and slaughtered in average after 42 days of growth. Whereas in Brazil, broiler chickens registered an average in live weight of $3 \mathrm{~kg}$ and slaughtered in average after 40 days (Assunção et al., 2017). By law, all chickens must have enough freedom of movement, be able to stand regularly, turn around and stretch their wings without difficulty. They should also have enough space to be able to sit without interference from other birds (DEFRA, 2018). For Van Horne \& Achterbosch (2008), Brazil is in a first level position of welfare whereas Switzerland is in a top position as welfare level.

Environmental enrichment can benefit animal welfare in a different way, such as health, strengthen the activity of broilers and particular behaviour that the species expresses in the natural habitat (Boere, 2001; Campo et al., 2005; Jones, 2004; Newsberry, 1995; Riber et al., 2018).

In agreement with Baxter \& O'Connell (2019) environmental enrichments to broiler chickens are generally created to increase low activity levels as well as encourage natural behaviours like perching and foraging. Castellini et al. (2002) concluded that organic systems presented more natural rearing conditions, broiler chickens increased motor activity, became less sensitive to stressors and gained muscle mass when compared with the conventional method. Jordan et al. (2011) found that the final body weight was 13\% lower in broilers with the feed scattered in the bedding once compared with the conventional feeding system.

This study aimed to analyse if environmental enrichment, sex, and age influence broiler chickens' weight during growth.

\section{MATERIALS AND METHODS}

The observational study was carried out in a commercial farm located in Mogi Mirim county $\left(22.42^{\circ}\right.$ S, 46.95 W), Brazil, from August to November 2016.
The farm had four broiler houses $(\mathrm{BH})$ with negative forced ventilation with blue lateral polypropylene curtain with similar design and construction (15 m wide $\times 150$ long $\times 3 \mathrm{~m}$ high). Each house housed approximately 30000 chickens and was equipped with identical automatic nipple drinkers and feeders. The litter material used for each house was new sawdust with rice husks.

A programme monitoring system controlled the rearing environment. The temperature for all houses was automatically reduced from $32^{\circ} \mathrm{C}$ (start period) to an end temperature of $18^{\circ} \mathrm{C}$ (finish period). The light program from 1-day- of age (20 Ix) to 7 days of age was continuous (24 L:0 D). A total of 8 hours was added from 8-days of age to 28-days of age until a total of 30 minutes of darkness per night was complete. From 28-days of age to the end of the flock, the light was in a natural condition without using artificial light in the darkness.

The composition of animal feed was produced by the farm where the study was carried out (starter, rearing, and finisher). Feed and drinking water were given ad libitum. In each broiler house, a metal rectangle frame that measured $5 \times 10 \times 3 \mathrm{~m}$ to control the broiler chickens was built (Figure 1). A total of fivehundred broiler chicken was housed with a density of 12 animals $/ \mathrm{m}^{2}$. For environmental enrichment, each broiler house received a different stimulus (Table 1).

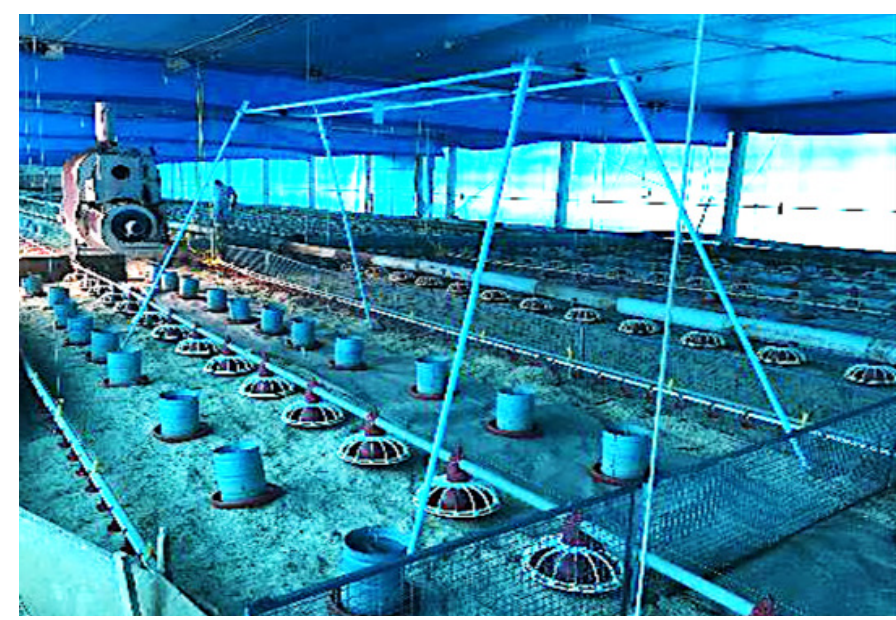

Figure 1 - Picture of the metal rectangle in the area of the studied broiler house

Table 1 - Environmental Enrichment type used in the trial.

\begin{tabular}{lc}
\hline Broiler house & Environmental Enrichment \\
\hline $\mathrm{BH} 1$ & Music and light \\
$\mathrm{BH} 2$ & Music \\
$\mathrm{BH} 3$ & Light \\
$\mathrm{BH} 4$ & Without environmental enrichment (control) \\
\hline
\end{tabular}

In $\mathrm{BH} 1$ and $\mathrm{BH} 2$ different music styles were played each week to promote motivation for the birds. Every week an amount of four types of sounds were played 
where the total time of duration was six minutes, and each one had 1 minute and 30 minutes of the time of period. The audio track was played five times a day for six weeks, starting from 9.00 AM to 5.00 PM with a pause of one hour within it. The type of sounds were rock, soul, country, jazz, pop, nature, and classical music (Campo et al., 2005; D'Avila et al., 2011).

Under $\mathrm{BH} 1$ and $\mathrm{BH} 3$, the light stimuli used came from a coloured (red and green) LED strobe projector (Xtrad, model LT-923159, São Paulo/SP-Brazil) (Figure 2). The light performed once a day, for five weeks. The duration of the light stimuli was about 6 minutes.



Figure 2 - The light dots from a coloured LED strobe projector.

The assessment was carried out for five weeks $(7,14$, 21,28 , and 35 days). Every week, in each metal square frame from the broiler houses $(\mathrm{BH})$ twenty broiler chickens (ten male and ten female), were caught and weighed.

For the statistical analysis, the exploratory data analyses was used, where graphics were developed (Boxplot) of the results of mean weight with significance range (95\% intervals for means). Therefore, it is possible to determine the effects of the environmental enrichment type, gender, and age, as well as the probable interactions of these variables, on the weight of broiler chickens. Following the analysis, the data was submitted to the comparative analysis of means, analysis of variance (ANOVA), followed by Tukey test of multiple comparisons.

\section{RESULTS AND DISCUSSION}

Body weight of broiler chickens 7, 14, and 21 day old broiler chickens did not differ when compared with age, gender, and environmental enrichment (broiler house) ( $p>0.05$, Figure 3). Moreover, with 28 and 25 days of age, broiler chickens showed difference in body weight $(p<0.05)$. The age appears as a strong influence on the birds' development. Abdullah et al. (2010) reported that at seven days of age, body weight differed $(p<0.05)$ among gender and strains and at 21 days of age males and females had comparable body weights to the present study. Castellini et al. (2002) observed that live, carcass weight, and feed efficiency were significantly affected by age and production system (organic and conventional).

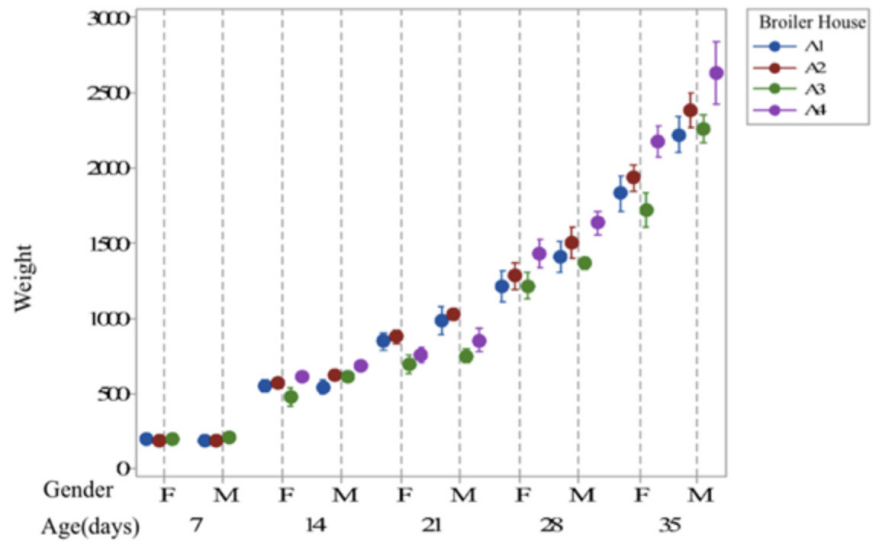

Figure 3 - Broiler chickens average body weight according to broiler house, gender, and age.

The gender of 7- and 14-day old broilers did not impact on body weight ( $p>0.05$ ), although males of 21 days old showed an increase in body weight when compared with female. However, it is notable that gender has synchrony by age. Bokkers \& Koene (2002) observed that males were heavier than females of 3 weeks of age similar to the present study. For Abdullah et al. (2010), a significant interaction by strain (Ross, Lohman, and Hubbard) and gender was also reported through 21-35 days. Zaghari et al. (2002) reported that male chicks grew faster than female, but no significant interaction by sex of lysine level was observed for weight gain. However, Kryeziu et al. (2018) noticed that no differences were seen between male and female broiler chickens on different ages $(7,14,21,28$ and 35 days old) and body weight in several stocking densities.

The body weight and environmental enrichment (broiler houses) had no interaction until birds were 21 days old; however, from 28 days of age it was possible to observe a strong correlation $(p<0.05)$. The broiler house (3) with light enrichment presented the lowest body weight when compared with all broiler houses. On the other hand, broiler house 4 without 
enrichment presented the highest body weight when compared with other broiler houses. Castellini et al. (2002) observed that organic broiler chickens presented lower growth performance when compared with the conventional environment. The light motivates the animals move rather than sit down. Simsek et al. (2009) recorded that body weight of broiler chickens in the control group after 42 days of age was $2291 \mathrm{~g}$ when compared with the body weight of broiler chickens in the environment enrichment group which was 2231 g. It seems that environmental enrichment stimulates the animal to improve the behaviour. Although, Ohara et al. (2015) concluded that the activity in birds reared with perches and hay bales did not affect productivity.

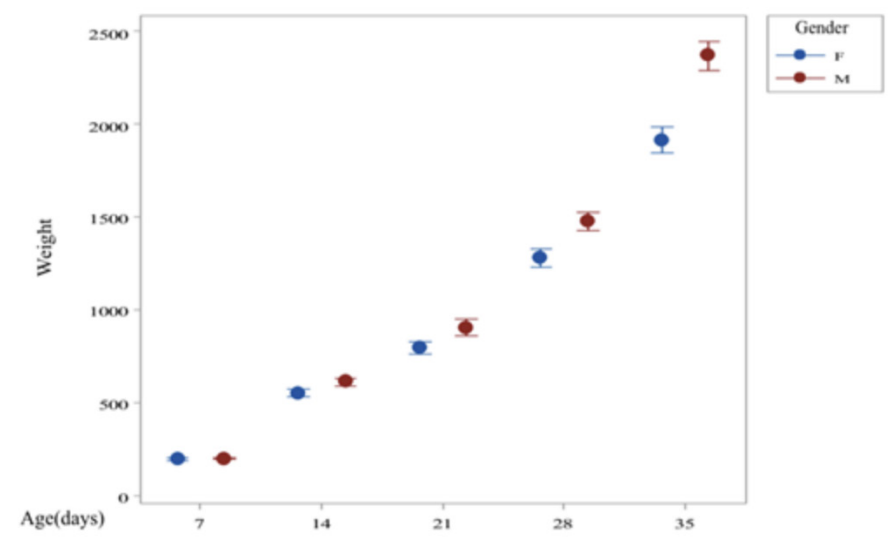

Figure 4 - Broiler chickens' average weight according to gender and age.

There was an interaction between environmental enrichment and gender.

For both genders, the body weight performed similarly through the days of the age where the stimuli did not alter the physiology of the bird. Females of 35 days of age showed the lowest body weight in broiler house with light when compared with other males. Bokkers \& Koene (2002) noticed an interaction for the motivation effect between the type of feed and gender where the motivation was lower for the female in a conventional type of feed than for free-range feed. In Djukic et al. (2009), the environment enrichment affected body weight. Broiler chicken grew 13\% significantly slower in a type of feed (pellets) where feed was scattered in the litter when compared with conventional treatment. Ohara et al. (2015) observed that the birds that presented low weekly body weight gain and low weight prefer perch than feed. Bizeray et al. (2002) concluded that perch and barrier as an environmental enrichment did not affect the body weight averages in the 3rd week.

In Figure 5 the performance of the environmental enrichment, body weight and age attend a pattern where broiler house 4 (control) displayed the highest weight, followed by broiler house 2 (music), broiler house
1 (music and light) and broiler house 3 (light) exhibited the lowest weight position. Moreover, 7 and 14 days old broiler chickens do not show a significant difference.

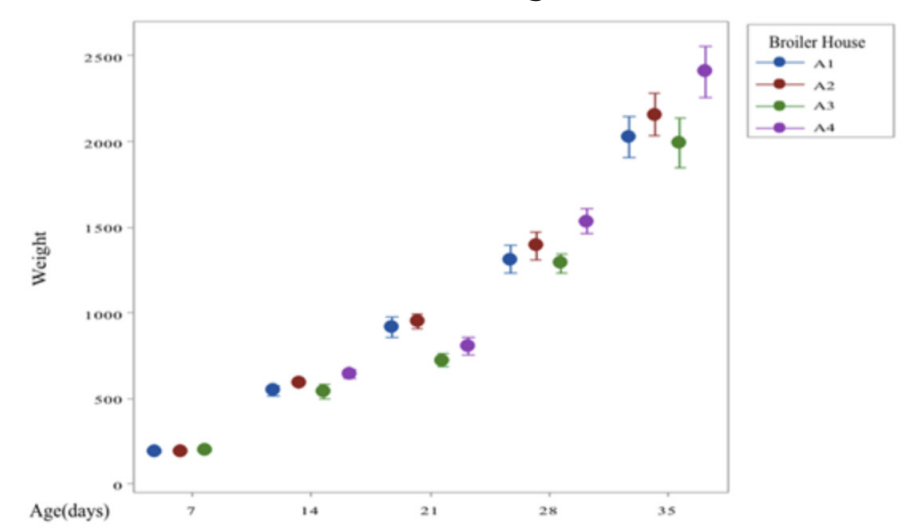

Figure $\mathbf{5}$ - Broiler chickens' average weight according to broiler house and age.

Lighting is an essential factor in the management of animals that can affect their productivity, health, and welfare (Alvino et al., 2009). Foss et al. (1972) concluded that Coturnix females presented lighter body weight and brooded under blue and green light compared to females kept under white and red light. Prayitno et al. (1997) observed that broiler chickens reared under blue light had $36.2 \mathrm{~g} / \mathrm{d}$ body weight and $34.7 \mathrm{~g} / \mathrm{d}$ under red light. Late red light for birds appears to contribute to lightest bone weight, bone strength, and body weight. Andreazzi et al. (2018) observed that broiler chickens in a conventional broiler house presented an average of $2.720 \mathrm{~kg}$ and $2.806 \mathrm{~kg}$ in a broiler house with a dark curtain (Dark House). Farghly et al. (2019) observed that broiler chickens exposed to flashing light and an intermittent feeding regime had the highest body weight and lowest feed conversion rate when compared with the control treatment. Lei \& Van Beek (1997) established that broiler chickens in high activity had higher body weight and feed intake than in normal activity state. Broiler house 4 (control) presented the typical situation in a broiler chicken farm and showed the highest body weight. Leone et al. (2010) concluded that group size, density, and size of the barn affects on movement and space use in broilers. Environmental complexity modify activity in broiler chickens (Bizeray et al., 2002). For Dawkins et al. (2003), increase ranging is associated with better health and welfare grounds.

\section{CONCLUSION}

The environmental enrichment affected broiler chicken weight according to the bird age increase. Broiler house $(\mathrm{BH} 3)$ with light as stimuli showed the lowest body weight and broiler house $(\mathrm{BH} 4)$ presented the highest body weight. 


\section{REFERENCES}

Abdullah AY, Al-Beitawi NA, Rjoup MMS, Qudsieh RI, Ishmais MAA. Growth performance, carcass and meat quality characteristics of different commercial crosses of broiler strains of chicken. Journal Poultry Science 2010;47(13):13-21

ABPA - Associação Brasileira de Proteína Animal. Relatórios anuais [cited 2019 Jan 10]. São Paulo; 2018. Available from: http://www.abpa-br. com.br.

Alvino, GM, Archer, GS, Mench, JA. Behavioural time budgets of broiler chickens reared in varying light intensities. Applied Animal Behaviour Science 2009;118:54-61.

Andreazzi MA, Pinto JS, Santos JMG, Cavalieri FLB, Matos NCS, Barbieri IO. Desempenho de frangos de corte criados em aviário convencional e dark-house. Revista da Universidade Vale do Rio Verde 2018;16(1):1-6.

Assunção ASA, Garcia RG, Komiyam ACM, Gandra ERS, Martins RA, Silva TIS, et al. Medidas físicas dos filés de peitos de frangos de corte acometidos com miopatia peitoral (Wooden breast). Anais do $4^{\circ}$ Workshop de Pós-Graduação em Zootecnia e Ciência Animal e $4^{\circ}$ Encontro Científico da Zootecnia; 2017. Aquiduana, Mato Grosso do Sul. Brasil.

Baxter M, O'Connell NE. Does grouping environmental enrichments together affect the way they are used by commercially housed broiler chickens? Applied Animal Behaviour Science 2019;210:52-59.

Bizeray D, Estevez I, Leterrier C, Faure JM. Effects of increasing environmental complexity on the physical activity of broiler chickens. Applied Animal Behaviour Science 2002;79:27-41.

Boere V. Behavior and environment enrichment. In: Fowler ME, Cubas ZS. Biology, medicine and surgery of South American wild animals. Iowa: lowa State University Press; 2001. p.263-266.

Bokkers EAM, Koene P. Sex and type of feed effects on motivation and the ability to walk for a food reward in fast growing broilers. Applied Animal Behaviour Science 2002;79:247-261

Campo JL, Gil MG, Davila SG. Effects of specific noise and music stimuli on stress and fear levels of laying hens of several breeds. Applied Animal Behaviour Science 2005:91:75-84

Carreiro J. Pela volta do frango caipira [cited 2019 Feb 15]. São Paulo: Estadão; 2017 . Available from: www.estadao.com.br

Castellini C, Mugnai C, Dal Bosco A. Effect of organic production system on broiler carcass and meat quality. Meat Science 2002;60:219-225.

Davila SG, Campo JL, Gil MG, Prieto MT, Torres O. Effects of auditory and physical enrichment on 3 measurements of fear and stress (tonic immobility duration, heterophil to lymphocyte ratio, and fluctuating asymmetry) in several breeds of layer chicks. Poultry Science 2011;90:2459-2466

Dawkins MS, Cook PA, Whittingham MJ, Mansell KA, Harper AE. What makes free-range broiler chickens range? In situ measurement of habitat preference. Animal Behaviour 2003:66:151-160.

DEFRA - Department for Environment Food \& Rural Affairs. Broiler (meat) chickens: welfare recommendations [cited 2019 Feb 2]. Londres; 2018. Available from: www.gov.uk/government/publications/poultry-onfarm-welfare.

Council Directive 2007/43/EC and its influence on the welfare of chickens kept for meat production, as well as the development of welfare indicators. Bruxellas: European Comission; 2018.
Farghly MF, Mahrose KM, Ahmad EAM, Rehman ZU, Yu S. Implementation of different feeding regimes and flashing light in broiler chicks. Poultry Science 2019:98(5):2034-2042

Foss DC, Carew Jr LB, Arnold EL. Physiological development of cockerels as influenced by selected wavelengths of environmental light. Poultry Science 1972;51:1922-1927

Jones RB. Environmental enrichment:the need for practical strategies to improve poultry welfare. in welfare of the laying hen. Wallingford: CABI Publishing; 2004.

Jordan D, Stuhec I, Bessei W. Effect of whole wheat and feed pellets distribution in the litter on broilers' activity and performance. Archiv Geflügelkunde 2011;75(2):98-103.

Kryeziu AJ, Mestani N, Berisha S, Kamberi MA. The European performance indicators of broiler chickens as influenced by stocking density and sex. Agronomy Research 2018;16(2):483 491

Lei S, Van Beek G. Influence of activity and dietary energy on broiler performance, carcase yield and sensory quality. British Poultry Science 1997;38(2):183-189.

Leone EH, Christman MC, Douglas L, Estevez I. Separating the impact of group size, density, and enclosure size on broiler movement and space use at a decreasing perimeter to area ratio. Behavioural Processes 2010;83:16-22

Meluzzi A, Fabbri C, Folegatti E, Sirri F. Effect of less intensive rearing conditions on litter characteristics, growth performance, carcase injuries and meat quality of broilers. British Poultry Science 2008;49(5):509515 .

Molento CFM. Animal welfare and production: economic aspects - Review. Archives of Veterinary Science 2005;10(1):1-11.

Mollo MN, Vendrametto O, Okano MT. Precision livestock tools to improve products and processes in broiler production: a review. Brazilian Journa of Poultry Science 2009;11(4): 211-218.

Newsberry RC. Environmental enrichment: increasing the biological relevance of captive environments. Applied Animal Behavior Science 1995;44: 229-243.

Ohara A, Oyakawa C, Yoshihara Y, Ninomiya S, Sato S. Effect of environmental enrichment on the behavior and welfare of japanese broilers at a commercial farm. Journal Poultry Science 2015;52:323330.

Prayitno DS, Phillips CJC, Stokes DK. The Effects of color and intensity of light on behavior and leg disorders in broiler chickens. Poultry Science 1997:76:1674-1681.

Riber AB, Van de Weerd HA, Jong IC, Steenfeld S. Review of environmental enrichment for broiler chickens. Poultry Science 2018;97:378-396.

Robins A, Phillips CJC. International approaches to the welfare of meat chickens. World's Poultry Science Journal 2011;67:351-369.

Simsek UG, Dalkilic B, Ciftci M, Cerci IH, Bahs, M. Effects of enriched housing design on broiler performance, welfare, chicken meat composition and serum cholesterol. Acta Veterinaria Brno 2009;78:67-74.

Van Horne PLM, Achterbosch TJ. Animal welfare in poultry production systems: impact of European Union standards on world trade. World's Poultry Science Journal 2008;64(1):40-52.

Zaghari M, Shivazad M, Kamyab A, Nikkhah A. Digestible lysine requirement of arian male and female broiler chicks during six to twenty-one days of age. Journal. Agriculture Science Technology 2002;4:111-117. 
